\title{
Enthalpy of Solvation Correlations for Gaseous Solutes Dissolved in Water and in 1-Octanol Based on the Abraham Model
}

\author{
Christina Mintz, ${ }^{\dagger}$ Michael Clark, ${ }^{\ddagger}$ William E. Acree, Jr., ${ }^{*} \dagger$ and Michael H. Abraham ${ }^{\S}$ \\ Department of Chemistry, P.O. Box 305070, University of North Texas, Denton, Texas 76203-5070, \\ Department of Research and Statistical Support, P.O. Box 305398, University of North Texas, \\ Denton, Texas 76203-5070, Department of Chemistry, University College London, 20 Gordon Street, \\ London, WC1H 0AJ, United Kingdom
}

Received September 15, 2006

\begin{abstract}
Data have been assembled on the enthalpies of solvation of 373 compounds in water and 138 compounds in 1-octanol. It is shown that an Abraham solvation equation with five descriptors can be used to correlate the experimental solvation enthalpies to within standard deviations of $3.68 \mathrm{~kJ} / \mathrm{mol}$ (water) and $2.66 \mathrm{~kJ} / \mathrm{mol}$ (1-octanol). The derived correlations provide very accurate mathematical descriptions of the observed enthalpies of solvation, which in the case of water span a range of $150 \mathrm{~kJ} / \mathrm{mol}$. Division of the experimental values into a training set and a test set shows that there is no bias in predictions and that the predictive capability of the correlations is better than $4 \mathrm{~kJ} / \mathrm{mol}$.
\end{abstract}

\section{INTRODUCTION}

The air-to-water and air-to-octanol partition coefficients, $K_{\mathrm{W}}$ and $K_{\mathrm{OTOH}}$, as well as their temperature dependence, are used in predicting the fate and transport of volatile organic compounds (VOCs) in the environment. Of particular interest are the processes involving the partition of VOCs from the gas phase into natural water systems and water droplets, and into systems containing natural organic matter. Measured airto-octanol partition coefficient data have been used with success to describe the partitioning behavior of organic compounds between the gas phase and soils, ${ }^{1,2}$ plants, ${ }^{3-7}$ aerosols, ${ }^{8-11}$ and human faeces. ${ }^{12}$ Temperature dependence of $K_{\mathrm{W}}$ and $K_{\mathrm{OTOH}}$ is needed to predict the effect of ambient temperature changes on environmental phase distribution, to explain the accumulation of VOCs in remote mountainous regions and cold arctic climates, and to describe the release of organic contaminants from melting ice and snow. A recent paper ${ }^{13}$ addressed the misinterpretations that can result whenever the temperature dependence is not taken into account.

In order to improve the quality of experimental data used in environmental modeling computations, Cole and Mackay ${ }^{14}$ have developed procedures for evaluating the consistency of experimental solubility data, air-to-water and air-to-organic partition coefficients using known thermodynamic relationships. Their "three-solubility" approach allows missing property data to be estimated. The approach also identifies inconsistencies in reported values. Knowledge of the temperature dependence of $K_{\mathrm{W}}$ and $K_{\text {Отон helps in establishing }}$ part of the evaluation criteria.

\footnotetext{
* Corresponding author fax: (940) 565-4318; e-mail: acree@unt.edu.

† Department of Chemistry, University of North Texas.

$\doteqdot$ Department of Research and Statistical Support, University of North Texas.

$\S$ University College London.
}

To date, we have developed linear free energy correlations for the gas-to-water coefficients: ${ }^{15}$

$$
\begin{array}{r}
\log K_{\mathrm{W}}=-1.271+0.822 E+2.743 S+3.904 A+ \\
4.814 B-0.213 L
\end{array}
$$

and gas-to-octanol partition coefficients: ${ }^{16}$

$$
\begin{array}{r}
\log K_{\mathrm{OTOH}}=-0.119-0.203 E+0.560 S+3.576 A+ \\
0.702 B+0.940 L
\end{array}
$$

based on the Abraham solvation parameter model. Both correlations pertain to a temperature of $298.15 \mathrm{~K}$. The independent variables, or descriptors, in eqs 1 and 2 are solute properties, as we have discussed before several times. ${ }^{17-20}$ $E$ is the solute excess molar refractivity in units of $\left(\mathrm{dm}^{3}\right.$ $\left.\mathrm{mol}^{-1}\right) / 10 ; S$ is the solute dipolarity/polarizability; $A$ and $B$ are the solute overall or summation hydrogen bond acidity and basicity, and $L$ is the logarithm of the solute gashexadecane partition coefficient at $298.15 \mathrm{~K}$ The regression coefficients and constants ( $c, e, s, a, b$, and $l$ ) are obtained by regression analysis of experimental results for a given process (i.e., a given partitioning process and so forth). For partition coefficients involving two condensed phases, the $c, e, s, a, b$, and $l$ coefficients represent differences in the solvent phase properties. Note that, for the gas-to-water partition, an alternative equation in which the descriptor $V$ replaces $L$ yields a slightly better correlation. ${ }^{15} V$ is the McGowan volume in units of $\left(\mathrm{dm}^{3} \mathrm{~mol}^{-1}\right) / 100$.

In the present study, we are expanding our considerations to other temperatures and properties by developing Abraham model correlations for the enthalpies of solvation of gaseous solutes, $\Delta_{\text {Solv }} H^{\circ}$, in both water and 1-octanol. The derived enthalpic correlations, when combined with eqs 1 and 2, allow one to estimate the gas-to-water and gas-to-octanol 
partition coefficients at temperatures not too far removed from $298.15 \mathrm{~K}$.

$\log K_{\mathrm{W}}($ at $T)-\log K_{\mathrm{W}}($ at $298.15 \mathrm{~K})=\frac{-\Delta_{\mathrm{Solv}} H_{\mathrm{W}}{ }^{\circ}}{R}$

$(1 / T-1 / 298.15)$

In principle one could develop a separate gas-to-liquid phase

$$
\begin{aligned}
\log K_{\mathrm{OTOH}}(\text { at } T)-\log K_{\mathrm{OTOH}}(\text { at } 298.15 K) & = \\
& \frac{-\Delta_{\text {Solv }} H_{\mathrm{OTOH}}{ }^{\circ}}{R}(1 / T-1 / 298.15)
\end{aligned}
$$

partition correlation for each temperature to be studied as was recently done for the partitioning of gaseous solutes into 1-hexadecanol. ${ }^{21}$ It is unlikely however that one would be able to find sufficient experimental data to develop meaningful correlations at more than just one or two select temperatures. To get around this problem, we have elected to integrate enthalpies of solvation into our predictive method and thus have derived correlation equations based on measured $\Delta_{\text {Solv }} H^{\circ}$ data for solutes dissolved in both water and 1-octanol. The enthalpic correlations use the same set of solute descriptors as do our existing equations for solute transfer from the gas phase, so no additional information is required. For informational purposes, we note that Abraham and co-workers used earlier versions of the basic model to correlate the enthalpies of transfer of 86 solutes from water to hexadecane $\mathrm{e}^{22}$ and the enthalpies of transfer of 25 aliphatic and aromatic solutes from aqueous solution to 2,2,4trimethylpentane. ${ }^{23}$ Our study differs from the two earlier works in that we are correlating enthalpies of transfer from the gas phase rather than the enthalpies of transfer between two condensed phases. Moreover, the present study involves considerably more compounds, and we have included an assessment of the predictive capability of each derived correlation by constructing separate training and test data sets.

There have been but few previous attempts to correlate $\Delta_{\text {Solv }} H_{\mathrm{W}}{ }^{\circ}$ values and, as far as we are aware, only two to correlate $\Delta_{\text {Solv }} H_{\mathrm{OTOH}^{\circ}}{ }^{\circ}$ values. Cabani et al. ${ }^{24}$ set out a fragmentation scheme for $197 \Delta_{\text {Solv }} H_{\mathrm{W}}{ }^{\circ}$ values. For the 128 compounds that generated "reliable" parameters, they fitted the $\Delta_{\text {Solv }} H_{\mathrm{W}}{ }^{\circ}$ values with a standard deviation of only 1.7 $\mathrm{kJ} / \mathrm{mol}$; however, no fewer than 48 structural (fragment) parameters were used in the calculation. Kühne et al. ${ }^{25}$ studied a much larger database of 456 compounds and fitted $\Delta_{\text {Solv }} H_{\mathrm{W}}{ }^{\circ}$ values to give a standard deviation of $7.1 \mathrm{~kJ} / \mathrm{mol}$ with 46 structural parameters. Plyasunov and co-workers ${ }^{26-30}$ have also set out fragmentation schemes for $\Delta_{\text {Solv }} H_{\mathrm{W}}{ }^{\circ}$, but these are restricted to specific compounds (for example, aliphatic esters or aliphatic ethers). As regards the correlation of $\Delta_{\text {Solv }} H_{\mathrm{OTоH}^{\circ}}{ }^{\circ}$ values, only Bernazzani et al. ${ }^{31,32}$ have reported any scheme, and that for a limited number of compounds only.

\section{EXPERIMENTAL METHODS}

Our search of the chemical literature found compilations of enthalpy of solvation data for 456 and 89 solutes dissolved in water $^{22,24}$ and 1-octanol, ${ }^{31-33}$ respectively, plus several papers $^{34-69}$ that reported experimental partial molar enthalpies of solution of liquid and crystalline organic compounds. The latter data were determined by either direct calorimetric methods or calculated on the basis of the temperature dependence of measured infinite dilution activity coefficient data, and the published values were converted to gas-to-water and/or gas-to-octanol enthalpies of transfer by subtracting the solute's standard molar enthalpy of vaporization, ${ }^{70}$ $\Delta_{\mathrm{Vap}} H_{298 \mathrm{~K}}{ }^{\circ}$, or standard molar enthalpy of sublimation, ${ }^{71}$ $\Delta_{\mathrm{Sub}} H_{298 \mathrm{~K}}{ }^{\circ}$, at $298.15 \mathrm{~K}$.

$$
\text { liquid solutes: } \Delta_{\text {Solv }} H^{\circ}=\Delta_{\text {Soln }} H^{\circ}-\Delta_{\text {Vap }} H_{298 \mathrm{~K}}^{\circ}
$$

For purposes of the this study, we have considered enthalpies

$$
\text { crystalline solutes: } \Delta_{\text {Solv }} H^{\circ}=\Delta_{\text {Soln }} H^{\circ}-\Delta_{\text {Sub }} H_{298 \mathrm{~K}}^{\circ}
$$

of solvation, $\Delta_{\text {Solv }} H^{\circ}$, and what will be called "inner energies", $\Delta_{\text {Solv }} U$, to be equivalent. Goss ${ }^{72}$ discusses the difference between the $\Delta_{\text {Solv }} H^{\circ}$ and $\Delta_{\text {Solv }} U$ in terms of the concentration units used in expressing the gas-phase concentrations of the Henry's law constant. At $298 \mathrm{~K}$, the difference between the quantities amounts to about $2.5 \mathrm{~kJ} /$ mol, ${ }^{72}$ which is less than the experimental uncertainty associated with many of the observed values. Given the slight numerical difference between the two values under normal environmental conditions, we have combined both sets of numerical values into a single database, as has been done in the past by most research groups that have developed predictive methods for enthalpies of solvation. Most of our tabulated values are enthalpies of solvation; however, there may be a few "inner energies" listed in Tables S1 and S2 (Supporting Information) that were mislabeled as enthalpies in the original data source.

On the basis of an initial assessment of the available experimental data, we eliminated from consideration all experimental data that pertained to temperatures outside of the temperature range of $283-318 \mathrm{~K}$, or values from published compilations for which we could not find the original data source. Enthalpies of solvation are temperaturedependent, and we did not want to introduce large errors in the database by including experimental data far removed from $298 \mathrm{~K}$. Also excluded were values based on solubility measurements where the equilibrium solid phase might be either a hydrated (or solvated) form of the solid solute or values that might contain appreciable contributions from solute dissociation (ionization). For several solutes, there were multiple, independently determined values. In such cases, we selected direct calorimetric data over indirect values based on the temperature dependence of measured solubilities or infinite dilution activity coefficients. Using the aforementioned criteria, 373 molar enthalpies of solvation in water and 138 molar enthalpies of solvation in 1-octanol were selected for regression analysis. The experimental $\Delta_{\text {Solv }} H_{\mathrm{W}}{ }^{\circ}$ and $\Delta_{\text {Solv }} H_{\mathrm{OTOH}}{ }^{\circ}$ values are listed in Tables S1 and S2 of the Supporting Information, respectively.

Molecular descriptors for all of the compounds considered in the present study are also tabulated in Tables S1 and S2. The numerical values in Tables S1 and S2 came from our solute descriptor database, which now contains values for more than 3500 different organic and organometallic compounds. The descriptors were obtained exactly as described 


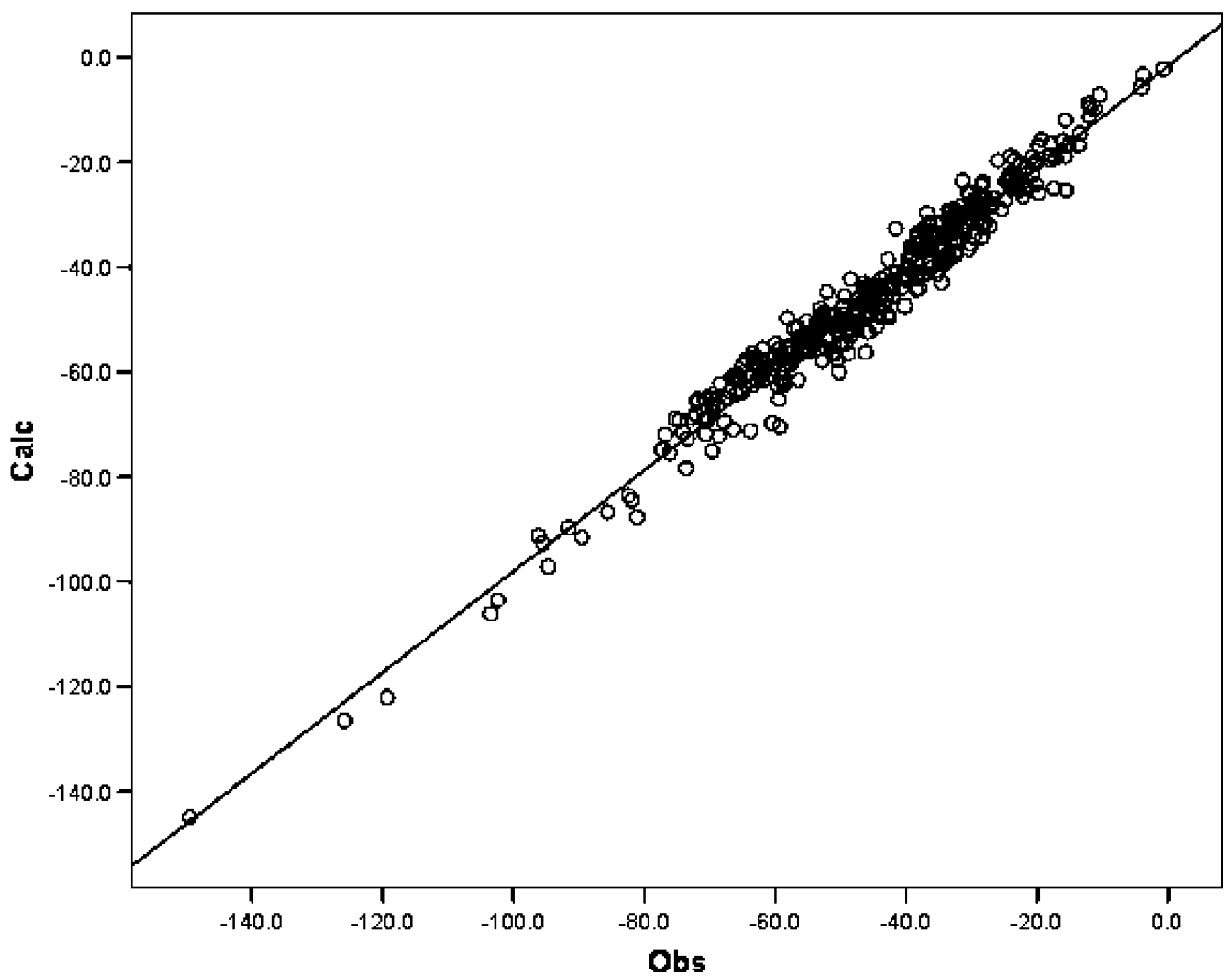

Figure 1. Plot of the calculated values of $\Delta_{\text {Solv }} H_{\mathrm{W}}{ }^{\circ}$ on eq 7 against the observed values.

before, using various types of experimental data, including water-to-solvent partitions, gas-to-solvent partitions, solubilities, and chromatographic data. ${ }^{18}$ Solute descriptors used in the present study are all based on experimental data. There is also commercial software ${ }^{73}$ and several published estimation schemes ${ }^{74-77}$ available for calculating the numerical values of solute descriptors from molecular structural information if one is unable to find the necessary partition, solubility, and/or chromatographic data.

\section{RESULTS AND DISCUSSION}

Enthalpies of Solvation in Water. Our literature search found enthalpies of solvation for 372 compounds dissolved in water at $298 \mathrm{~K}$. Initial analysis of the experimental data given in Table S1 indicated 4-chlorophenol, $\mathrm{N}$-methylpyrrolidine, tetrachloroethylene, and 1-octylamine to be outliers. In the case of octylamine, we believe that the experimental value should be considerably more exothermic. Enthalpies of solvation for the alkylamines-methylamine $\left(\Delta_{\text {Solv }} H_{\mathrm{W}}{ }^{\circ}=\right.$ $-45.3 \mathrm{~kJ} / \mathrm{mol})$, ethylamine $\left(\Delta_{\text {Solv }} H_{\mathrm{W}}{ }^{\circ}=-53.7 \mathrm{~kJ} / \mathrm{mol}\right)$, 1-propylamine $\left(\Delta_{\mathrm{Solv}} H_{\mathrm{W}}{ }^{\circ}=-56.0 \mathrm{~kJ} / \mathrm{mol}\right), 1$-butylamine $\left(\Delta_{\text {Solv }} H_{\mathrm{W}}{ }^{\circ}=-59.0 \mathrm{~kJ} / \mathrm{mol}\right)$, 1-pentylamine $\left(\Delta_{\text {Solv }} H_{\mathrm{W}}{ }^{\circ}=\right.$ $-62.1 \mathrm{~kJ} / \mathrm{mol})$, and 1-hexylamine $\left(\Delta_{\text {Solv }} H_{\mathrm{W}}{ }^{\circ}=-65.9 \mathrm{~kJ} /\right.$ mol)-become more exothermic with increasing alkyl chain length. ${ }^{22}$ The experimental value for 1-octylamine, $\Delta_{\text {Solv }} H_{\mathrm{W}}{ }^{\circ}$ $=-52.3 \mathrm{~kJ} / \mathrm{mol},{ }^{25}$ does not follow the observed trend. Similarly, the measured value for 4-chlorophenol of $\Delta_{\text {Solv }} H_{\mathrm{W}}{ }^{\circ}$ $=-35.9 \mathrm{~kJ} / \mathrm{mol}$ is far out of line with the value for 3-chlorophenol of $\Delta_{\mathrm{Solv}} H_{\mathrm{W}}{ }^{\circ}=-50.3 \mathrm{~kJ} / \mathrm{mol}$. The four outliers were removed from the data set, and the final regression analysis was performed to yield

$$
\begin{gathered}
\Delta_{\text {Solv }} H_{\mathrm{W}}{ }^{\circ}(\mathrm{kJ} / \mathrm{mol})=-13.310(0.457)+ \\
9.910(0.814) E+2.836(0.807) S-32.010(1.102) A- \\
41.816(0.781) B-6.354(0.200) L \\
\left(\text { with } N=368, \mathrm{SD}=3.68, R^{2}=0.964, R_{\text {adj }}{ }^{2}=\right. \\
0.964, F=1950.5)
\end{gathered}
$$

One additional compound, erythritol, was used in developing

$$
\begin{gathered}
\Delta_{\text {Solv }} H_{\mathrm{W}}{ }^{\circ}(\mathrm{kJ} / \mathrm{mol})=-6.952(0.651)+ \\
1.415(0.770) E-2.859(0.855) S-34.086(1.225) A- \\
42.686(0.850) B-22.720(0.800) V \\
\left(\text { with } N=369, \mathrm{SD}=4.04, R^{2}=0.959, R_{\text {adj }}^{2}=\right. \\
0.958, F=1688.2)
\end{gathered}
$$

eq 8. Erythritol's enthalpy of solvation is $\Delta_{\text {Solv }} H_{\mathrm{W}}{ }^{\circ}=-114$ $\mathrm{kJ} / \mathrm{mol}$, and there are very few compounds in our database having large negative enthalpies of solvation. We could not include erythritol in the eq 7 regression analyses because its $L$ descriptor is not known. Here and elsewhere, $N$ corresponds to the number of solutes, $R$ denotes the correlation coefficient, SD is the standard deviation, and $F$ corresponds to the Fisher $\mathrm{F}$ statistic. All regression analyses were performed using SPSS statistical software. ${ }^{78}$ Both eqs 7 and 8 are statistically very good, with standard deviations of 3.7 and $4.0 \mathrm{~kJ} / \mathrm{mol}$ for a data set that covers a range of $150 \mathrm{~kJ} /$ mol (see Figures 1 and 2 where plots of the calculated values of $\Delta_{\text {Solv }} H_{\mathrm{W}}{ }^{\circ}$ on eqs 7 and 8 against the observed values are shown). It is interesting that the rare gases, inorganic gases, 


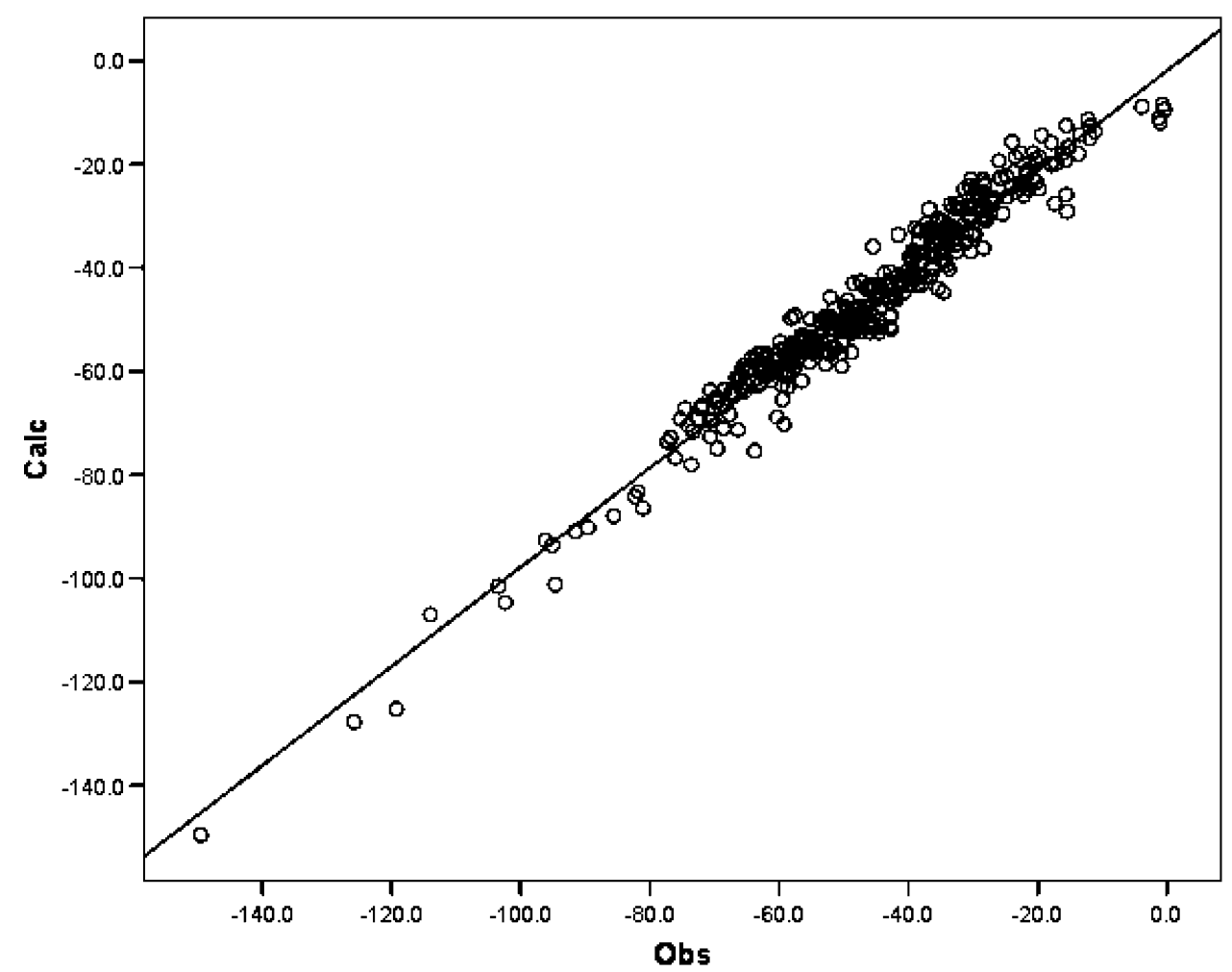

Figure 2. Plot of the calculated values of $\Delta H_{\mathrm{Solv}, \mathrm{W}}{ }^{\circ}$ on eq 8 against the observed values.

and polyaromatic hydrocarbons all fit eqs 7 and 8 , and yet they do not fit the corresponding equations in the gas-towater partition coefficient. ${ }^{15}$ Equation 7 is slightly the better equation statistically, but eq 8 might be useful in cases where the $L$ descriptor is not known. Note that, because the McGowan volume, $V$, is calculated from the individual atomic sizes and numbers of bonds in the molecule, ${ }^{79}$ it is always known.

There have been but few previous attempts to correlate $\Delta_{\text {Solv }} H_{\mathrm{W}}{ }^{\circ}$ values. Cabani et al. ${ }^{24}$ set out a fragmentation scheme for $197 \Delta_{\text {Solv }} H_{\mathrm{W}}{ }^{\circ}$ values. For the 128 compounds that generated "reliable" parameters, they fitted the $\Delta_{\text {Solv }} H_{\mathrm{W}}{ }^{\circ}$ values with a standard deviation of only $1.7 \mathrm{~kJ} / \mathrm{mol}$; however, no fewer than 48 structural (fragment) parameters were used in the calculation. Kühne et al. ${ }^{25}$ studied a much larger database of 456 compounds and fitted $\Delta_{\text {Solv }} H_{\mathrm{W}}{ }^{\circ}$ values to give a standard deviation of $7.1 \mathrm{~kJ} / \mathrm{mol}$ using 46 structural parameters. In comparison, our method uses only five independent variables to fit 368 data points to within 3.7 $\mathrm{kJ} / \mathrm{mol}$ on eq 7. As an informational note, Kühne et al. did not provide literature references for the 456 gas-to-water enthalpies of transfer used in their study. In building our database, we included values from the Kühne et al. study only if we were able to find the original literature reference so that we could verify that the experimental values pertained to temperatures at or near $298 \mathrm{~K}$ and were based on measured enthalpy of vaporization data, rather than estimated $\Delta_{\mathrm{Vap}} H_{298 \mathrm{~K}}{ }^{\circ}$ values. The authors did mention that they had taken steps to validate their database; however, in the written text, the authors stated that the maximum value of $\Delta_{\text {Solv }} H_{\mathrm{W}}{ }^{\circ}$ is 108 $\mathrm{kJ} / \mathrm{mol}$ and that a temperature range of between 0 and 100 ${ }^{\circ} \mathrm{C}$ is covered. Enthalpies of solvation are temperaturedependent, and for our intended applications, we prefer the values to pertain to temperatures at or near 298 K. Moreover, the large enthalpy of vaporization database of Chickos and Acree ${ }^{70}$ does not have $\Delta_{\mathrm{Vap}} H_{298 \mathrm{~K}}{ }^{\circ}$ values for some of the liquid compounds from the Kühne et al. study. Before including such compounds in our database, we wanted to see how the $\Delta_{\mathrm{Vap}} H_{298 \mathrm{~K}}{ }^{\circ}$ values were obtained. Plyasunov and co-workers have also set out fragmentation schemes for $\Delta_{\text {Solv }} H_{\mathrm{W}}{ }^{\circ}$, but these are restricted to specific compounds (for example, aliphatic esters or aliphatic ethers). Maikut and coworkers ${ }^{80}$ correlated the enthalpy of solvation of 37 organic compounds in water with a six-parameter equation. The compounds studied by the authors covered a much smaller range of experimental values, $\Delta_{\text {Solv }} H_{\mathrm{W}}{ }^{\circ}=24.7-91.2 \mathrm{~kJ} /$ mol, and the resulting root-mean-square (RMS) deviation of RMS $=4.48 \mathrm{~kJ} / \mathrm{mol}$ was larger than that found for either eqs 7 or 8 . The authors did exclude three solutes (cyclohexanone, dimethoxyethane, and diethyl ether) from their original data set of 40 compounds to get to a squared correlation coefficient of $R^{2}=0.91$.

Goss $^{72}$ recently proposed an indirect method for estimating the enthalpies of solvation of organic compounds on the basis of the Abraham solvation model. The author used the experimental gas-to-water partition coefficients at $298 \mathrm{~K}$ reported by Abraham et al., ${ }^{15}$ along with the enthalpies of solvation compiled by Kühne et al., to calculate the gas-towater partition coefficients at several temperatures between 273 and $318 \mathrm{~K}$. A separate $\log K_{\mathrm{W}}$ correlation was derived for each temperature studied. The derived $\log K_{\mathrm{W}}$ correlations were then used to generate predicted $\log K_{\mathrm{W}}$ values at each temperature, which were then plotted versus $1 / T$. Enthalpies of solvation were back-calculated from the slopes of the resulting $\log K_{\mathrm{W}}$ versus $1 / T$ curves for each of the 217 compounds studied. No statistical information was given in the paper comparing the back-calculated and observed $\Delta_{\text {Solv }} H_{\mathrm{W}}{ }^{\circ}$ values; however, the graphical comparison that the 
author presented showed deviations as large as $10-15 \mathrm{~kJ} /$ mol for many of the 217 compounds. Equation 7 provides a more accurate prediction of $\Delta_{\mathrm{Solv}} H_{\mathrm{W}}{ }^{\circ}$ than the indirect method of Goss. For most of the 368 compounds that we studied, the predicted and observed values differed by less than $5 \mathrm{~kJ} / \mathrm{mol}$. Neither Cabani et al. nor Schüürmann et al. nor Maikut and co-workers nor Goss assessed the predictive capability of their method by use of training sets and test sets.

In order to assess the predictive ability of eq 7, we divided the 368 data points into a training set and a test set by allowing the SPSS software ${ }^{77}$ to randomly select half of the experimental data points. The selected data points became the training set, and the compounds that were left served as the test set. Analysis of the experimental data in the training set gave

$$
\begin{aligned}
\Delta_{\text {Solv }} H_{\mathrm{W}}{ }^{\circ}(\mathrm{kJ} / \mathrm{mol}) & =-13.572(0.635)+ \\
9.211(1.174) E+ & 1.748(1.003) S-31.460(1.561) A- \\
& 41.665(1.103) B-6.008(0.280) L
\end{aligned}
$$

with $N=184, \mathrm{SD}=3.58, R^{2}=0.967, R_{\mathrm{adj}}^{2}=0.966$, and $F$ $=1029.4$. There is very little difference in the equation coefficients for the full data set and training data set correlations. The training set was then used to predict $\Delta_{\text {Solv }} H_{\mathrm{W}}{ }^{\circ}$ values for the 184 compounds in the test set. For the predicted and experimental values, we find that $\mathrm{SD}=$ 3.83 , average absolute error $(\mathrm{AAE})=3.19$, and average error $(\mathrm{AE})=-0.16$. There is therefore very little bias in the predictions using eq 7 with $\mathrm{AE}$ equal to $-0.16 \mathrm{~kJ} / \mathrm{mol}$. The test and training set analyses were performed three times. A more detailed description of the analyses is provided in Tables S4-S6 in the Supporting Information. This seems to be the first time that any predictive assessment of an equation for $\Delta_{\text {Solv }} H_{\mathrm{W}}{ }^{\circ}$ has been made.

Enthalpies of Solvation in Octanol. In Table S2 (Supporting Information) are collected values of the enthalpies of solvation in octanol for 138 compounds. ${ }^{22,31-33,42,49-52,62-65}$ Application of the general eqs 1 and 2 leads to eqs 10 and 11.

$$
\begin{gathered}
\Delta_{\mathrm{Solv}} H_{\mathrm{OTоH}}{ }^{\circ}=-6.49(0.57)-1.04(1.13) E+ \\
5.89(1.39) S-53.99(2.39) A-8.99(1.36) B- \\
9.18(0.18) L
\end{gathered}
$$

(with $N=138, \mathrm{SD}=2.66, R^{2}=0.988, F=2242.0$ )

Although both eqs 10 and 11 are statistically reasonable, eq

$$
\begin{aligned}
& \Delta_{\text {Solv }} H_{\text {Отон }}{ }^{\circ}=+1.57(1.19)-13.34(1.75) E+ \\
& \quad 0.32(2.37) S-58.76(4.10) A-7.63(2.33) B-34.05
\end{aligned}
$$

$$
\text { (with } N=138, \mathrm{SD}=4.53, R^{2}=0.966, F=752.0 \text { ) }
$$

10 is appreciably better than eq 11 , and it is eq 10 that we would recommend for any predictions of values of $\Delta_{\mathrm{Solv}} H_{\mathrm{O}}$ $\mathrm{TOH}^{\circ}$. Equation 10 is also better than the corresponding equation for $\Delta_{\mathrm{Solv}} H_{\mathrm{W}}{ }^{\circ}$, with $\mathrm{SD}=2.66 \mathrm{~kJ} / \mathrm{mol}$ as compared to $3.68 \mathrm{~kJ} / \mathrm{mol}$; eq 10 covers a range of $97 \mathrm{~kJ} / \mathrm{mol}$, which not quite as large as the range covered by eq $7,150 \mathrm{~kJ} / \mathrm{mol}$.
As for all the equations of the type of eq 1 that we have used to correlate gas-to-solvent partition coefficients, eq 10 covers the rare gases and other inorganic gases as well as polyaromatic hydrocarbons, the polychlorobiphenyls, and the polychloronaphthalenes, so it is a very general equation indeed. Fortunately, we have descriptors for all the polychlorobiphenyls ${ }^{81}$ and all the polychloronaphthalenes,${ }^{82}$ and so it is then trivial to predict $\Delta_{\mathrm{Solv}} H_{\text {Отон }}{ }^{\circ}$ for these important environmental pollutants.

In order to assess the predictive capability of eq 10 , we chose a training set, as before; application of eq 1 resulted in eq 12:

$$
\begin{aligned}
& \Delta_{\text {Solv }} H_{\text {Отон }}{ }^{\circ}=-6.48(0.83)-1.24(1.54) E+ \\
& \quad 7.35(1.95) S-54.81(3.11) A-8.42(1.81) B-9.38
\end{aligned}
$$

$$
\text { (with } N=69, \mathrm{SD}=2.60, R^{2}=0.989, F=1180.1 \text { ) }
$$

Within the given SD values, the coefficients of eq 12 are the same as those in eq 10, indicating that the training set covers a similar chemical space to that of the total set. When the training equation was used to predict values of $\Delta_{\text {Solv }} H_{\mathrm{O}}$ $\mathrm{TOH}^{\circ}$ for the remaining 69 compounds in the test set, we found for the predictions that $\mathrm{AE}=0.08, \mathrm{AAE}=2.07, \mathrm{SD}=2.79$, and RMSE $=2.77 \mathrm{~kJ} / \mathrm{mol}$. There is almost no bias in the predictions, and these statistics confirm that the full equation can be used to predict further values of $\Delta_{\mathrm{Solv}} H_{\mathrm{Oтон}}{ }^{\circ}$ to within a SD of about $2.8 \mathrm{~kJ} / \mathrm{mol}$. Minitab software was used for all of the 1-octanol regressions.

We are aware of one group method and an earlier application of the Abraham model for estimating enthalpies of solvation in 1-octanol. Bernazzani et al. ${ }^{31}$ predicted the $\Delta_{\text {Solv }} H_{\text {Отон }}{ }^{\circ}$ values of 89 compounds in 1-octanol to within a standard deviation of $1.37 \mathrm{~kJ} / \mathrm{mol}$ using 21 structural fragment values deduced by a multiple least-squares regression analysis of the entire data set. The authors' second method, in which the $\mathrm{CH}_{2}$ group value was preassigned an average of the increments of the enthalpies of solvation in homologous series of alkanes, ethers, 1-alkanols, ketones, and chloroalkanes, gave a slightly larger standard deviation of $2.96 \mathrm{~kJ} / \mathrm{mol}$. Our method of eq 10 is quite comparable and predicts the enthalpies of solvation compounds in 1-octanol to within a standard deviation of $2.66 \mathrm{~kJ} / \mathrm{mol}$ using just five independent variables. Bernazzani et al. ${ }^{32}$ described the $\Delta_{\mathrm{Solv}} H_{\text {Отон }}{ }^{\circ}$ of 29 compounds in 1-octanol using the Abraham equation and molecular descriptors. The authors obtained a standard deviation of $0.25 \mathrm{~kJ} / \mathrm{mol}$ for their correlation equation for the 29 compounds that spanned an approximate range of $40 \mathrm{~kJ} / \mathrm{mol}$.

Supporting Information Available: Enthalpy of solvation data for compounds in water and in 1-octanol, numerical values of the solute descriptors for the compounds studied, and training and test set analyses for water. This material is available free of charge via the Internet at http://pubs.acs.org.

\section{REFERENCES AND NOTES}

(1) Hippelein, M.; McLachlanm, M. S. Soil/Air Partitioning of Semivolatile Organic Compounds. 1. Method Development and Influence of Physical-Chemical Properties. Environ. Sci. Technol. 1998, 32, $310-31$. 
(2) Cousins, I. T.; Beck, A. J.; Jones, K. C. A Review of the Processes Involved in the Exchange of Semi-Volatile Organic Compounds (SVOC) Across the Air-Soil Interface. Sci. Total Environ. 1999, 228, 5-24.

(3) Thomas, G.; Sweetman, A. J.; Ockenden, W. A.; Mackay, D.; Jones, K. C. Air-Pasture Transfer of PCBs. Environ. Sci. Technol. 1998, 32, 936-942.

(4) Weiss, P. Vegetation/Soil Distribution of Semivolatile Organic Compounds in Relation to Their Physicochemical Properties. Environ. Sci. Technol. 2000, 34, 1707-1714.

(5) Tolls, J.; McLachlan, M. S. Partitioning of Semivolatile Organic Compounds between Air and Lolium Multiflorum (Welsh Ray Grass). Environ. Sci. Technol. 1994, 28, 159-166.

(6) Hiatt, M. H. Bioconcentration Factors for Volatile Organic Compounds in Vegetation. Anal. Chem. 1998, 70, 851-856.

(7) Welke, B.; Ettlinger, K.; Riederer, M. Sorption of Volatile Organic Chemicals in Plant Surfaces. Environ. Sci. Technol. 1998, 32, 10991104.

(8) Finizio, A.; Mackay, D.; Bidleman, T.; Harner, T. Octanol-Air Partition Coefficient as a Predictor of Partitioning of Semi-Volatile Organic Chemicals to Aerosols. Atmos. Environ. 1997, 31, 22892296.

(9) Kaupp, H.; McLachlan, M. S. Gas/Particle Partitioning of PCDD/Fs, PCBs, PCNs and PAHs. Chemosphere 1999, 38, 3411-3421.

(10) Lohmann, R.; Lee, R. G. M.; Green, N. J. L.; Jones, K. C. GasParticle Partitioning of PCDD/Fs in Daily Air Samples. Atmos. Environ. 2000, 34, 2529-2537.

(11) Falconer, R. L.; Harner, T. Comparison of the Octanol-Air Partition Coefficient and Liquid-Phase Vapor Pressure as Descriptors for Particle/Gas Partitioning Using Laboratory and Field Data for PCBs and PCNs. Atmos. Environ. 2000, 34, 4043-4046.

(12) Moser, G. A.; McLachlan, M. S. Partitioning of Polychlorinated Biphenyls and Hexachlorobenzene into Human Faeces. Environ. Sci. Technol. 2002, 36, 3318-3325.

(13) Goss, K.-U.; Wania, F.; McLachlan, M. S.; Mackay, D.; Schwarzenbach, R. P. Comment on "Reevaluation of Air-Water Exchange Fluxes of PCBs in Green Bay and Southern Lake Michigan”. Environ. Sci. Technol. 2004, 38, 1626-1628.

(14) Cole, J. G.; Mackay, D. Correlating Environmental Partitioning Properties of Organic Compounds: The Three-Solubility Approach. Environ. Toxicol. Chem. 2000, 19, 265-270.

(15) Abraham, M. H.; Andonian-Haftvan, J.; Whiting, G. S.; Leo, A.; Taft R. W. Hydrogen Bonding. Part 34: The Factors that Influence the Solubility of Gases and Vapours in waTer at $298 \mathrm{~K}$, and a New Method for Its Determination. J. Chem. Soc., Perkin Trans. 2 1994, 17771791.

(16) Abraham, M. H.; Le, J.; Acree, W. E., Jr.; Carr, P. W.; Dallas, A. J. The Solubility of Gases and Vapours in Dry Octan-1-ol at $298 \mathrm{~K}$ Chemosphere 2001, 44, 855-863.

(17) Abraham, M. H. Scales of Hydrogen Bonding: Their Construction and Application to Physicochemical and Biochemical Processes. Chem. Soc. Rev. 1993, 22, 73-83.

(18) Abraham, M. H.; Ibrahim, A.; Zissimos, A. M. The Determination of Sets of Solute Descriptors from Chromatographic Measurements. $J$. Chromatogr., A 2004, 1037, 29-47.

(19) Abraham, M. H.; Acree, W. E., Jr. Correlation and Prediction of Partition Coefficients between the Gas Phase and Water, and the Solvents Dodecane and Undecane. New J. Chem. 2004, 28, 15381543.

(20) Abraham, M. H.; Acree, W. E., Jr. The Correlation and Prediction of Butane/Water and Gas/Butane Partition Coefficients. Can J. Chem. Eng. 2005, 83, 362-365.

(21) Xiao, H.; Lei, Y. D.; Wania, F. Determination of Partitioning Coefficients of Numerous Organic Solutes between a Long-Chain Aliphatic Alcohol and the Gas Phase as a Function of Temperature. J. Chem. Eng. Data 2006, 51, 338-346.

(22) Abraham, M. H.; Whiting, G. S.; Fuchs, R.; Chambers, E. J. Thermodynamics of Solute Transfer from Water to Hexadecane. $J$. Chem. Soc., Perkin Trans. 2 1990, 291-300.

(23) Fuchs, R.; Abraham, M. H.; Kamlet, M. J.; Taft, R. W. Solute-Solvent Interactions in Chemical and Biological Systems. IV. Correlations of $\Delta \mathrm{G}, \Delta \mathrm{H}$ and $\mathrm{T} \Delta \mathrm{S}$ of Transfer of Aliphatic and Aromatic Solutes from 2,2,4-Trimethylpentane to Aqueous Solution. J. Phys. Org. Chem. 1989, 2, 559-564.

(24) Cabani, S.; Gianni, P.; Mollica, V.; Lepori, L. Group Contributions to the Thermodynamic Properties on Non-Ionic Organic Solutes in Dilute Aqueous Solution. J. Solution Chem. 1981, 8, 563-595.

(25) Kühne, R.; Ebert, R.-U.; Schüürmann, G. Prediction of the Temperature Dependency of Henry's Law Constant from Chemical Structure. Environ. Sci. Technol. 2005, 39, 6705-6711.

(26) Plyasunov, A. V.; Plyasunova, N. V.; Shock, E. L. Group Contribution Values for the Thermodynamic Functions of Hydration at $298.15 \mathrm{~K}$,
0.1 MPa. 3. Aliphatic Monoethers, Diethers, and Polyethers. J. Chem. Eng. Data 2006, 51, 276-290.

(27) Plyasunov, A. V.; Plyasunova, N. V.; Schock, E. L. Group Contribution Values for the Thermodynamic Functions of Hydration at $298.15 \mathrm{~K}$, 0.1 MPa. 4. Aliphatic Nitriles and Dinitriles. J. Chem. Eng. Data 2006, $51,1481-1490$

(28) Plyasunova, N. V.; Plyasunov, A. V.; Shock, E. L. Group Contribution Values for the Thermodynamic Functions of Hydration at 298.15 K, $0.1 \mathrm{MPa}$. 2. Aliphatic Thiols, Alkyl Sulfides, and Polysulfides. J. Chem. Eng. Data 2005, 50, 246-253.

(29) Plyasunov, A. V.; Plyasunova, N. V.; Shock, E. L. Group Contribution Values for the Thermodynamic Functions of Hydration of Aliphatic Esters at 298.15 K, 0.1 MPa. J. Chem. Eng. Data 2004, 49, 11521167.

(30) Plyasunov, A. V.; Shock, E. L. Group Contribution Values of the Infinite Dilution Thermodynamic Functions of Hydration for Aliphatic Noncyclic Hydrocarbons, Alcohols, and Ketones at 298.15 K and 0.1 MPa. J. Chem. Eng. Data 2001, 46, 1016-1019.

(31) Bernazzani, L.; Gianni, P.; Mollica, V.; Pizzolla, P. Group Contributions to Enthalpies of Solvation in Octan-1-ol and di-n-Butyl ether. Thermochim. Acta 2004, 418, 109-116.

(32) Bernazzani, L.; Carosi, M. R.; Ceccanti, N.; Conti, G.; Gianni, P.; Mollica, V.; Tine, M. R.; Lepori, L.; Matteoli, E. Thermodynamic Study of Organic Compounds in di-n-Butyl Ether. Enthalpy and Gibbs Energy of Solvation. Phys. Chem. Chem. Phys. 2000, 2, 4829-4836.

(33) Cabani, S.; Conti, G.; Mollica, V.; Bernazzani, L. Thermodynamics Study of Organic Compounds in Octan-1-ol. 4. Free Energy and Enthalpy Changes for the Process of Transfer from Gas and from Dilute Aqueous Solutions of Some Alkanes and Monofunctional Saturated Organic Compounds. J. Chem. Soc., Faraday Trans. 1991, 87, 2433-2442.

(34) Atik, Z.; Gruber, D.; Krummen, M.; Gmehling, J. Measurement of Activity Coefficients at Infinite Dilution of Benzene, Toluene, Ethanol, Esters, Ketones, and Ethers at Various Temperatures in Water Using the Dilutor Technique. J. Chem. Eng. Data 2004, 49, 1429-1432.

(35) Segatin, N.; Klofutar, C. Thermodynamics of Solution of Some Alkyl Acetates in Water. Monatsh. Chem. 2001, 132, 1451-1462.

(36) Bertrand, G. L; Millero, F. J ; Wu, C. Hepler, L. G. Thermochemical Investigations of the Water-Ethanol and Water-Methanol Solvent Systems. I. Heats of Mixing, Heats of Solution, and Heats of Ionization of Water. J. Phys. Chem. 1966, 70, 699-705.

(37) Koga, Y.; Westh, P.; Nishikawa, K. Excess Partial Molar Entropy of Alkane-mono-ols in Aqueous Solutions at $25^{\circ} \mathrm{C}$. Can. J. Chem. 2003 , $81,150-155$

(38) Krishnan, C. V.; Friedman, H. L. Solvation Enthalpies of Various Nonelectrolytes in Water, Propylene Carbonate, and Dimethyl Sulfoxide. J. Phys. Chem. 1969, 73, 1572-1580.

(39) Costa, F. S.; Eusebio, M. E.; Redinha, J. S.; Leitao, M. L. P. Enthalpies of Solvation of Hydroxyl Cyclohexane Derivatives in Different Solvents. J. Chem. Thermodyn. 1999, 31, 895-903.

(40) Freire, M. G.; Razzouk, A.; Mokbel, I.; Jose, J.; Marrucho, I. M. Coutinho, J. A. P. Solubility of Hexafluorobenzene in Aqueous Salt Solutions from (280 to 340) K. J. Chem. Eng. Data 2005, 50, 237242

(41) Guedes, R. C.; Coutinho, K.; Cabral, B. J. C.; Canuto, S. Differential Hydration of Phenol and Phenoxy Radical and the Energetics of the Phenol O-H Bond in Solution. J. Phys. Chem. B 2003, 107, 43044310.

(42) Fuchs, R.; Stephenson, W. K. Enthalpies of Transfer of Alkane Solutes from the Vapor State to Organic Solvents. Can. J. Chem. 1985, 63, $349-352$.

(43) Abraham, M. H. Free Energies, Enthalpies, and Entropies of Solution of Gaseous Nonpolar Nonelectrolytes in Water and Nonaqueous Solvents. The Hydrophobic Effect. J. Am. Chem. Soc. 1982, 104, 2085-2094.

(44) Plyasunov, A. V.; Shock, E. L. Prediction of the Vapor-Liquid Distribution Constants for Volatile Nonelectrolytes in Water up to Its Critical Temperature. Geochim. Cosmochim. Acta 2003, 67, 49815009.

(45) Kustov, A. V.; Antonva, O. A.; Korolev, V. P. Enthalpies of 1,4Dioxane, 1,2-Dimethoxyethane, and Ethylacetate Solvation in the Water-1-Propanol and Water-Glycerol Binary Mixtures. J. Solution Chem. 2002, 31, 671-680.

(46) Lutsyk, A.; Portnanskij, V.; Sujkov, S.; Tchuprina, V. A New Set of Gas/Water Partition Coefficients for the Chloromethanes. Monatsh. Chem. 2005, 136, 1183-1189.

(47) Pollack, G. L.; Himm, J. F.; Enyeart, J. F. Solubility of Xenon in Liquid n-Alkanols: Thermodynamic Functions in Simple Polar Liquids. J. Chem. Phys. 1984, 81, 3239-3246.

(48) Bernazzani, L.; Conti, G.; Mollica, V. Enthalpies of Solution of Organic Compounds in Water/Octan-1-ol Mixtures. II. Bifunctional Saturated Compounds. J. Solution Chem. 2002, 31, 279-292. 
(49) Bhatia, S. R.; Sandler, S. I. Temperature Dependence of Infinite Dilution Activity Coefficients in Octanol and Octanol/Water Partition Coefficients of Some Volatile Halogenated Organic Compounds. J. Chem. Eng. Data 1995, 40, 1196-1198.

(50) Harner, T.; Bidleman, T. F. Measurement of Octanol-Air Partition Coefficients for Polycyclic Aromatic Hydrocarbons and Polychlorinated Naphthalenes. J. Chem. Eng. Data 1998, 43, 40-46.

(51) Wilcock, R. J.; Battino, R.; Danforth, W. F.; Wilhelm, E. Solubilities of Gases in Liquids. II. The Solubilities of $\mathrm{He}, \mathrm{Ne}, \mathrm{Ar}, \mathrm{Kr}, \mathrm{O}_{2}, \mathrm{~N}_{2}$, $\mathrm{CO}, \mathrm{CO}_{2}, \mathrm{CH}_{4}, \mathrm{CF}_{4}$ and $\mathrm{SF}_{6}$ in n-Octane, 1-Octanol, n-Decane and 1-Decanol. J. Chem. Thermodyn. 1978, 10, 817-822.

(52) Harner, T.; Bidleman, T. F. Measurements of Octanol-Air Partition Coefficients for Polychlorinated Biphenyls. J. Chem. Eng. Data 1996, 41, 895-899.

(53) Boyer, F. L.; Bircher, L. J. The Solubility of Nitrogen, Argon, Methane, Ethylene, and Ethane in Normal Primary Alcohols. J. Phys. Chem. 1960, 64, 1330-1331.

(54) Arnett, E. M.; Chawla, B. Complete Thermodynamic Analysis of the Hydration of Thirteen Pyridines and Pyridinium Ions. The Special Case of 2,6-di-tert-Butylpyridine. J. Am. Chem. Soc. 1979, 101, 71417146.

(55) Abraham, M. H. Thermodynamics of Solution of Homologous Series of Solutes in Water. J. Chem. Soc., Faraday Trans. 1 1984, 80, 153181.

(56) Shimotori, T.; Arnold, W. A. Henry's Law Constants of Chlorinated Ethylenes in Aqueous Alcohol Solutions: Measurement, Estimation, and Thermodynamic Analysis. J. Chem. Eng. Data 2002, 47, 183190.

(57) Rouw, A. C.; Somsen, G. The Solvation of Some Alcohols in Binary Solvents: Enthalpies of Solution and Enthalpies of Transfer. J. Chem. Thermodyn. 1981, 13, 67-76.

(58) Abraham, M. H.; Matteoli, E. The Temperature Variation of the Hydrophobic Effect. J. Chem. Soc., Faraday Trans. 1 1988, 84, 19852000.

(59) Nishino, N.; Morimoto, S.; Nakamura, M. Dissolution States of Normal Alkane Derivatives with a Polar Group in Water. Bull. Chem. Soc. Jpn. 1984, 57, 2797-2801.

(60) Nagamachi, M. Y.; Francesconi, A. Z. Measurement and Correlation of Excess Molar Enthalpy $\mathrm{HmE}$ for (1,2-Propanediol, or 1,3Propanediol, or 1,4-Butanediol + water) at the Temperatures (298.15, 323.15, and 343.15) K. J. Chem. Thermodyn. 2006, 38, 461-466.

(61) Koga, Y.; Siu, W. W. Y.; Wong, T. Y. H. Excess Partial Molar Free Energies and Entropies in Aqueous tert-Butyl Alcohol Solutions at $25^{\circ}$ C. J. Phys. Chem. 1990, 94, 7700-7706.

(62) IUPAC Solubility Data Series; IUPAC: Research Triangle, NC.

(63) Harner, T; Mackay, D. Measurement of Octanol-Air Partition Coefficients for Chlorobenzenes, PCBs, and DDT. Environ. Sci. Technol. 1995, 29, 1599-606.

(64) Gruber, D.; Langenheim, D.; Gmehling, J.; Moollan, W. Measurement of Activity Coefficients at Infinite Dilution Using Gas-Liquid Chromatography. 6. Results for Systems Exhibiting Gas-Liquid Interface Adsorption with 1-Octanol as the Solvent. J. Chem. Eng. Data 1997, 42, 882-885.

(65) Iloukhani, H. Excess Molar Enthalpies for Binary Mixtures with Trichloroethylene + Alkan-1-alkanols (C3-C8.) at 298.15 K. J. Chem. Eng. Data 1997, 42, 802-804.

(66) Purlee, E. L.; Taft, R. W., Jr.; DeFazio, C. A. Enthalpies and Entropies of Activation for the Hydration of Dissolved Isobutene and Trimeth- ylethylene from the Thermodynamic Properties for Solution of Gaseous Olefins in Aqueous Nitric Acid. J. Am. Chem. Soc. 1955, 77, 837842.

(67) Jozwiak, M. The Effect of Properties of Water-Organic Solvent Mixtures on the Solvation Enthalpy of 12-Crown-4, 15-Crown-5, 18Crown-6 and Benzo-15-crown-5 Ethers at 298.15 K. Thermochim. Acta 2004, 417, 31-41.

(68) Costa, F. S.; Eusebio, M. E.; Redinha, J. S.; Leitao, M.; Louisa, P. Enthalpies of Solvation of Hydroxyl Cyclohexane Derivatives in Different Solvents. J. Chem. Thermodyn. 1999, 31, 895-903.

(69) Jesus, A. J. L.; Tome, L. I. N.; Eusebio, M. E. S.; Redinha, J. S. Determination of the Enthalpy of Solute-Solvent Interaction from the Enthalpy of Solution: Aqueous Solutions of Erythritol and L-Threitol. J. Phys. Chem. B 2006, 110, 9280-9285.

(70) Chickos, J. S.; Acree, W. E., Jr. Enthalpies of Vaporization of Organic and Organometallic Compounds, 1880-2002. J. Phys. Chem. Ref. Data 2003, 32, 519-878.

(71) Chickos, J. S.; Acree, W. E., Jr. Enthalpies of Sublimation of Organic and Organometallic Compounds, 1910-2001. J. Phys. Chem. Ref Data 2002, 31, 537-698.

(72) Goss, K.-U. Prediction of the Temperature Dependency of Henry's Law Constant Using Poly-Parameter Linear Free Energy Relationships. Chemosphere 2006, 64, 1369-1374.

(73) PharmaAlgorithms, ADME Boxes, version 3.0; PharmaAlgorithms Inc.: Toronto, Ontario, Canada, 2006.

(74) Platts, J. A.; Butina, D.; Abraham, M. H.; Hersey, A. Estimation of Molecular Linear Free Energy Relation Descriptors Using a Group Contribution Approach. J. Chem. Inf. Comput. Sci. 1999, 39, 835845 .

(75) Jover, J.; Bosque, R.; Sales, J. Determination of Abraham Solute Properties from Molecular Structure. J. Chem. Inf. Comput. Sci. 2004, 44, 1098-1106.

(76) Arey, J. S.; Green, W. H., Jr.; Gschwend, P. M. The Electrostatic Origin of Abraham's Solute Polarity Parameter. J. Phys. Chem. B 2005, $109,7564-7573$.

(77) Metelet, F.; Rogalski, M. Experimental Determination and Prediction of the Gas-Liquid n-Hexadecane Partition Coefficients. J. Chromatogr., A 2001, 923, 153-163.

(78) SPSS, Data Mining, Statistical Analysis Software, Predictive Analysis, Predictive Analytics, Decision Support Systems. http://www.spss.com (accessed Nov 2006).

(79) Abraham, M. H.; McGowan, J. C. The Use of Characteristic Volumes to Measure Cavity Terms in Reversed-Phase Liquid Chromatography. Chromatographia 1987, 23, 245-246.

(80) Maikut, O. M.; Makitra, R. G.; Pal'chikova, E. Ya. Correlation of the Enthalpies of Hydration and Solution of Nonelectrolytes in Water with Their Physicochemical Characteristics. Russ. J. Gen. Chem. 2006, 76, 170-174.

(81) Abraham, M. H.; Al-Hussaini, A. J. M. Solvation Parameters for the 209 PCBs: Calculation of Physicochemical Properties. J. Environ. Monit. 2005, 7, 295-301.

(82) Abraham, M. H.; Al-Hussaini, A. J. M. Solvation Descriptors for the Polychloronaphthalenes: Estimation of Some Physicochemical Properties. J. Environ. Monit. 2001, 3, 377-381.

CI600402N 